\title{
Comparison of Physiotherapeutic Intervention Programs on Handgrip Force and Myoelectric Activity in Individuals with COPD
}

\author{
Suenny Marrocos de Lima Moura', Danilo de Macêdo Moura', Alessandra Feitosa Gonçalves', \\ Maria Alessandra Sipriano da Silva', Georgia Freire Paiva Winkeler², Simone dos Santos Maciel², \\ Clarice Maria de Lucena Martins ${ }^{4}$, Heleodório Honorato dos Santos ${ }^{3,4}$
}

\begin{abstract}
Background: Chronic obstructive pulmonary disease (COPD) modifies the electrical activity of accessory respiratory muscles, also leading to a marked peripheral muscular dysfunction, measured by the handgrip strength taken as an indicator of total body strength. Objective: To compare the effects of two different physiotherapeutic programs on handgrip strength and myoelectric activity in COPD patients. Methods: Participated in the study 17 individuals, randomly allocated into 2 groups: 1 ) Maneuvers: $62.7 \pm 15.4$ years, $1.65 \pm 0.12 \mathrm{~m}, 81.4 \pm 18.2 \mathrm{~kg}, \mathrm{BMI}: 29.9 \pm 5.0 \mathrm{~kg} / \mathrm{m}^{2} ; 2$ ) Threshold: $64.4 \pm 11.2$ years, $1.58 \pm 0.08 \mathrm{~m}, 70.7 \pm 9.4 \mathrm{~kg}, \mathrm{BMI}: 28.6 \pm 3.7 \mathrm{~kg} / \mathrm{m}^{2}, \mathrm{diagnosed}$ with COPD, submitted to surface electromyographic (sEMG) evaluation of sternocleidomatoid (SCM) and anterior scalene (AS), and handgrip strength, before and after the interventions. The data were analyzed with SPSS (20.0). Pared t-student and Wilcoxon tests were used to compare mean values of the handgrip strength and the Root Mean Square (RMS) of the sEMG signal (SCM and AS muscles), pre- and post-interventions. In addition, independent t-Student and Mann-Whitney tests were used to compare the RMS average of the sEMG signal between the right and left sides. Significant level was set at $5 \%$. Results: When comparing pre and post-intervention values, there was a significant increase for the Threshold group handgrip strength $(P=0.037)$. It was observed a sEMG activity of SCM and AS during dynamometry, vital capacity, forced vital capacity on inspiratory and expiratory pressure $(P<0.05)$ for both analyzed groups. In the comparison of the myoelectric activity between the right and left sides for the SCM and AS, there was a significant difference in handgrip strength $(P=0.009)$ and forced vital capacity $(P=0.001)$ of the SCM muscle, post intervention for the Threshold group. Conclusion: The proposed physiotherapeutic programs improved the overall muscle strength for the Threshold group and the electromyographic activity of SCM and AS in the 2 groups.This study was registered in ReBEC: RBR-4VGP58
\end{abstract}

Keywords: Respiratory Disease; Electromyography; Muscle Strength; Physiotherapy.

\section{INTRODUCTION}

Chronic obstructive pulmonary disease (COPD) is considered one of the leading causes of morbidity and mortality worldwide, being the fourth leading cause of death in the population, making it a public health challenge ${ }^{(1,2)}$. The Latin American Project for the Investigation of Obstructive Pulmonary Disease (PLATINO) found, through a study among people over 40 years-old in large cities of Latin America, that there is an increase in the number of cases of COPD with advancing age, being more prevalent in individuals older than 60 years of age ${ }^{(1)}$. These patients present weakness and decrease in inspiratory muscle strength, increasing the mechanical workload of the diaphragm due to airflow limitation ${ }^{(2)}$. In addition, the hyperinflation, inherent to COPD, promotes alteration on the recruitment of accessory respiratory muscles, increasing its overload. According to Gomes et al. ${ }^{(4)}$ and Correa et al. ${ }^{(5)}$, one way to evaluate the function of the respiratory musculature is through the recording of the electrical signal produced during the contraction of accessory muscles, such as: Sternocleidomastoid (SCM) and Anterior Scalene (AS). Some studies have shown that low muscle activity in COPD patients influences the body's general muscular trophism, thus leading to a decrease in protein synthesis and / or an acceleration of proteolysis, leading to a reduction in cross-sectional area of fast and slow contraction fibers ${ }^{(2,6)}$. Thus, these patients present low oxidative activity with predominance of the anaerobic system, which results in an early increase of lactic acid concentration in the blood and exercise intolerance, consequently decreasing their capacity and strength ${ }^{(2,7)}$.

In general, in these subjects, there is a marked peripheral muscle dysfunction ${ }^{(8,9)}$, reducing both upper and lower limbs strength ${ }^{(2)}$. According to Moreira and Alvarez ${ }^{(10)}$ and Schlüssel et al. ${ }^{(11)}$, one way of assessing the individual's overall

Corresponding author: Heleodório Honorato dos Santos. Endereço: Av. Mons. Odilon Coutinho, 191/402, Cabo Branco, João Pessoa-PB. CEP: $58045-120$. Fone: +55 83 99613-7900. E-mail: dorioufpb@gmail.com

${ }^{3}$ Departamento de Fisioterapia da Universidade Federal da Paraíba - UFPB, João Pessoa, Paraíba, Brasil.

4Programa Associado de Pós-Graduação em Educação Física (PAPGEF) - UPE/UFPB, João Pessoa, Paraíba, Brasil.

Full list of author information is available at the end of the article.

Financial Support: Conselho Nacional de Desenvolvimento Científico e Tecnológico - CNPq.

Submission date 27 October 2018; Acceptance date 03 December 2018; Publication date 27 December 2018. 
strength is through the handgrip dynamometry, as this is an indicator of the total body's muscle strength. In COPD patients, the physiotherapeutic intervention should be early, aiming to increase cardiopulmonary conditioning. Based on this, several treatments have been proposed to minimize dysfunctions and limit disease progression, such as the association of pulmonary rehabilitation and resistance training of the peripheral musculature. Treatment duration, postrehabilitation maintenance strategies, inspiratory and aerobic training intensity, and behavioral orientations are some of the successful strategies on rehabilitation programs ${ }^{(12,13)}$. In this sense, several authors who carried out studies associating the surface electromyography (sEMG) of the accessory muscles of respiration with the evaluations of respiratory maneuvers and test of global muscle strength observed significant alteration in the SCM muscle during the Expriratory Positive Airway Pressure (EPAP) maneuver ${ }^{(14)}$, improvement in exercise tolerance after aerobic intervention ${ }^{(15)}$, and increased muscle recruitment during the PImax maneuver ${ }^{(16)}$. However, according to Dumke et al. ${ }^{(17)}$, additional studies must be performed to evaluate the activation of the breathing accessory musculature. So we hypothesize that after physiotherapeutic intervention, there is an increase in manual muscle strength and a decrease in the electrical activity of the breathing accessory musculature (SCM and AS). Thus, the aim of this study is to evaluate the effects of a physiotherapeutic therapy program on the handgrip strength and SEMG of SCM and AS muscles in COPD patients.

\section{METHODS}

\section{Sample's characteristics}

The initial sample consisted of 23 subjects, who were randomly allocated into 2 groups (Maneuvers and Threshold). However, only 17 individuals completed the study. The "Maneuvers" group consisted of 7 individuals (5 males and 2 females: $62.7 \pm 15.4$ years, $1.65 \pm 0.12 \mathrm{~m}$, $81.4 \pm 18.2 \mathrm{~kg}$ and body mass index/BMI $\left.29.9 \pm 5.0 \mathrm{~kg} / \mathrm{m}^{2}\right)$; and the Threshold group of 10 individuals ( 4 males and 6 females: $64.4 \pm 11.2$ years, $1.58 \pm 0.08 \mathrm{~m}, 70.7 \pm 9.4 \mathrm{~kg}$, and body mass index/BMI $28.6 \pm 3.7 \mathrm{~kg} / \mathrm{m}^{2}$ ). To participate in the study, all patients should: 1 ) have a proven COPD diagnosis (clinical and imaging examination) and; 2 ) do not present neurological, cardiovascular and / or musculoskeletal problems, in addition to loss of cognitive ability that made it impossible to carry out the evaluation and / or the treatment program. However, 6 individuals (all from the Maneuvers group) declined in participating in the study: 2 did not meet the inclusion criteria and 4 dropped out (Figure 1 ).

For the sample size calculation, the G*Power 3.0.10 software was used and the procedures followed Beck's recommendations ${ }^{(18)}$. A priori, a power of 0.95 was adopted, considering a level of significance of $5 \%$, and an effect size of 0.8 . A total of 23 subjects was calculated. However, due to the sample loss, a power of 0.8 , a level of significance of $5 \%$, and an effect size of 0.75 was calculated, resulting in 16 individuals. This analysis was performed to reduce the probability of type II error and to determine the minimum number of subjects

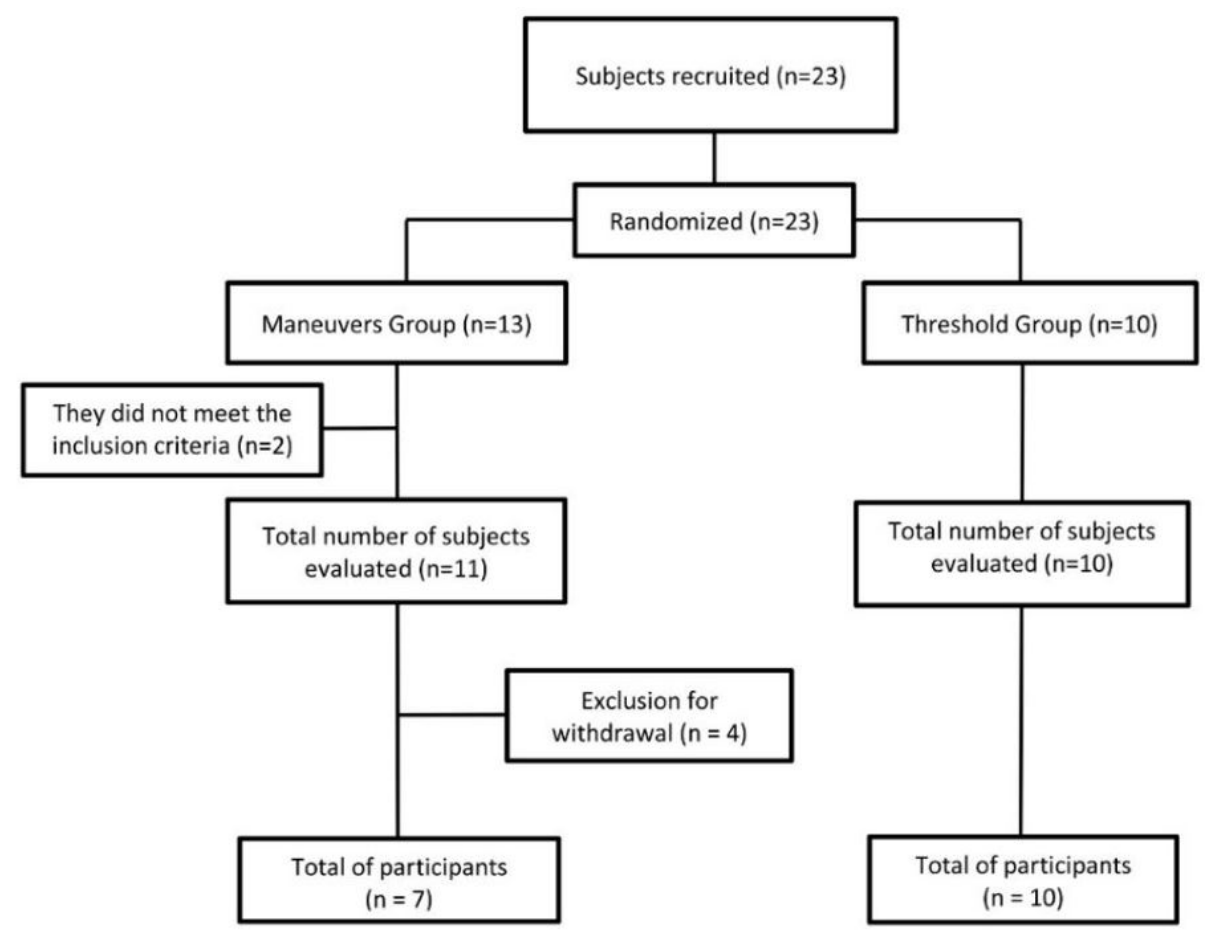

Figure 1. Sample Flow Diagram. 
required for the study. Thus, the sample size was sufficient to provide $80 \%$ statistical power.

The study was approved by the Research Ethics Committee of the Science and Health Center of the Federal University of Paraíba (CEP/CCS/UFPB), protocol number 0120/2014, CAAE: 30264914.0.0000.5188. All subjects were instructed about the study's aim and procedures and signed the Free and Informed Consent Form agreeing to participate, as established by the National Health Council (CNS, resolution 466/2012).

\section{Procedures}

To evaluate the electrical activity of SCM and AS muscles on both sides of the neck, an 8-channel bluetooth electromyograph (model W4X8, Biometrics Ltd., UK) was used, with the following technical characteristics: 12-bit analog-to-digital (A/D) conversion board hardware, 1000-fold gain amplifier, 20 to $500 \mathrm{~Hz}$ band pass filter (2nd order, Butterworth), common mode rejection ratio $(R R M C)>100 \mathrm{~dB}$, signal noise rate $<3 \mathrm{mV}$ (RMS), 109 Ohms impedance, with surface electrodes, bipolar, active, single differential, 20-fold preamplifier, reference electrode and DataLOG software for frequency collection and analysis sampling rate of $1000 \mathrm{~Hz}$. Before the data collect, tricotomy, abrasion and skin cleansing with $70 \%$ alcohol were performed, to decrease tissue impedance ${ }^{(19)}$. Then the electrodes were fixed at predetermined points of SCM and AS, according to Falla et al. ${ }^{(20)}$ and Dornelas-Andrade ${ }^{(21)}$, with double-sided adhesive tape and micropore, and the reference electrode was fixed in the styloid process of ulna.

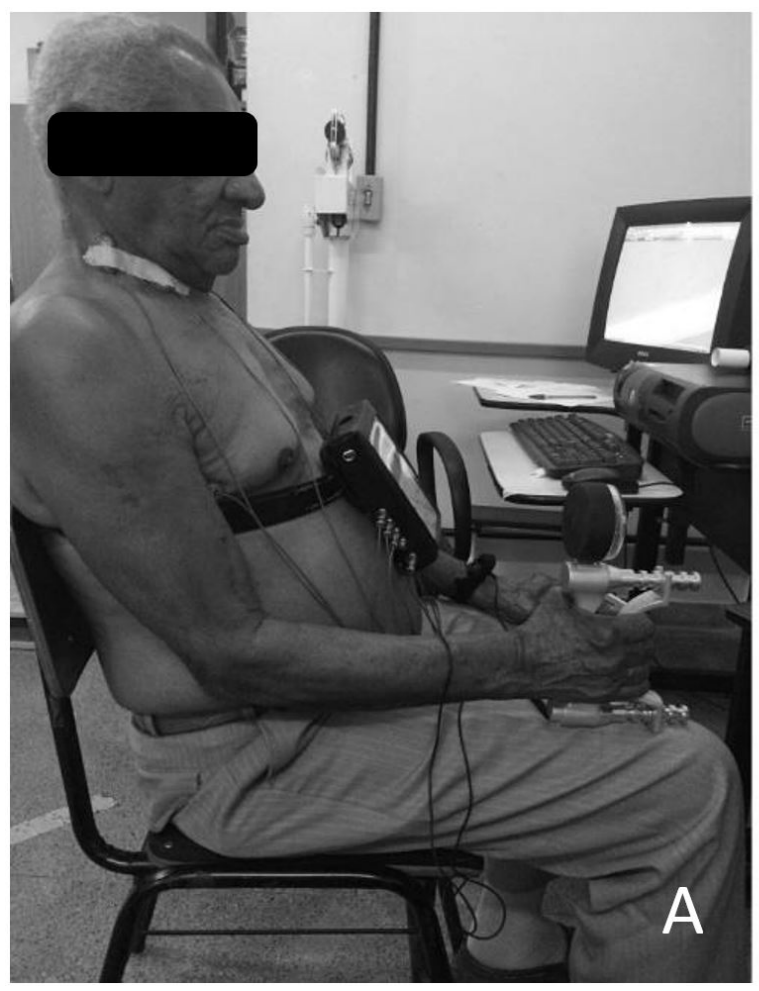

Figure 2. Handgrip measurement (A); Electrode fixation in SCM and SA (B).
Initially, the SEMG was recorded during the handgrip evaluation using a Lafayette Hydraulic Hand Dynamometer (Model J00105, Lafayett Instrument, IN - USA), according to standardized procedures proposed by the American Society of Hand Therapist (ASHT), in which the individual was seated with knees and hips flexed at $90^{\circ}$, shoulder adducted, elbow flexed at $90^{\circ}$ and forearm in neutral position ${ }^{(22,23)}$. Then, subjects were guided to perform the handgrip movement on the dominant limb (Figure 2A). A first test was done to familiarize individuals with the equipment. After that, three measurements ( 5 seconds of contraction each, and 1 minute of rest between them) were performed, preceded by a verbal stimulus (three, two, one and go) of the same evaluator for all the evaluated individuals ${ }^{(23,24)}$.

After the handgrip measurements, SCM and AS electromyography (Figure $2 \mathrm{~B}$ ) were recorded during the respiratory muscle strength's evaluation, simultaneously with maximal inspiratory and expiratory pressure maneuvers; and the evaluation of pulmonary function during vital capacity (VC) and forced vital capacity (FVC) maneuvers. During the electromyographic recording, no type of communication between the participants and the evaluator was allowed, in order to avoid altering respiratory mechanics. For the sEMG signal's processing, the Root Mean Square (RMS) was used, and for data normalization, the peak of the electromyographic signal was used.

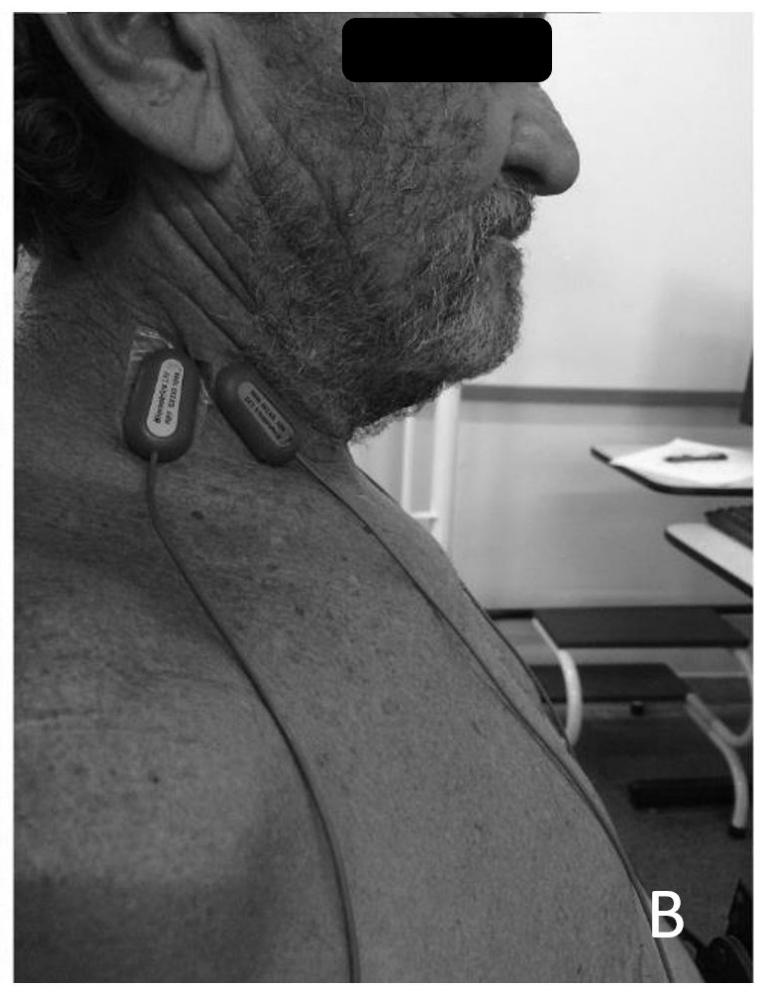

Figure 2. Handgrip measurement (A); Electrode fixation in SCM and $S A(B)$. 


\section{Intervention}

The treatment protocol was performed at the Clinical School of Physiotherapy (UFPB), 3 times / week, lasting 55 minutes each, and during 10 weeks. The sessions consisted of: a) 10 minutes stretching of the upper and lower limbs muscles; b) 15 minutes of upper and lower costal pompage, and SCM and AS muscles stretching; c) 15 minutes of respiratory techniques (inspiratory muscle training, using Threshold [Respiron - NCS, Brazil]) in $40 \%$ of PImax obtained during the first session of each week/thoracoabdominal re-education - TAR and acceleration of expiratory flow - AEF, respiratory functional re-education through diaphragmatic respiration and brake-labial respiration ${ }^{(24,25)}$; and d) aerobic training in the treadmill for 20 minutes (workload of $70 \%$ of maximal Heart Rate (HRmax $=220$-age), with 2.5 minutes of heating and 2.5 minutes of cool down.

\section{Data analysis}

The Statistical Package for the Social Sciences (SPSS - 20.0) software was used for statistical procedures. Data were tested for normality (Shapiro-Wilk), followed by the Paired t-Student test and Wilcoxon test, for comparisons of the handgrip strength average and the RMS of the SEMG signal for the SCM and AS muscles, pre and post intervention. For comparisons of the RMS average of the SEMG signal of the muscles (SCM and AS) between the right and left side, Independent t-student and Mann-Whitney tests were performed, considering a level of significance of $5 \%$. For comparisons of the anthropometric variables, the intra-class correlation (ICC) test was used, according to the following classification: null $=0.0$; weak $=0.01$ to 0.3 ; regular $=0.31$ to 0.6 ; strong $=0.61$ to 0.9 ; very strong $=0.91$ to $0.99 ;$ and full $=1.0 .{ }^{(26)}$

\section{Results}

The intra-class correlation (ICC) test showed very strong ( $r=0.91$ to 0.99 ) and significant $(P<0.001)$ correlations between groups (Maneuvers vs. Threshold) for age $(r=0.951 ; P<0.001)$, and anthropometric variables: Stature $(r=0.958 ; P<0.001)$ and $\mathrm{BMI}(r=0.902 ; \mathrm{P}=0.006)$, and a strong ( $r=0.61$ to 0.9$)$ correlation for Body Mass ( $r=0.758 ; P=0.048)$, according to Araújo et al. ${ }^{(26)}$. When comparing handgrip strength values between moments for the "Threshold" group, an increased strength value in the post-intervention measurement $(23.1 \pm 9.7 \times 26.6 \pm 7.9 ; \mathrm{P}=0.037)$ was observed. No difference was observed for the Maneuvers group (27.9 $\pm 9.8 \times 31.1 \pm 9.9 ; P=0.113)$. The Maneuvers group`s electromyographic activity (RMS) showed statistically significant difference before and after intervention for the following tests: 1 - Dynamometry (SCM_Right: $P=0.002$; SCM_Left: $P=0.010$ and AS_Left: $P=0.018) ; 2$ - Vital Capacity (SCM _Right: $P=0.018$; SCM _Left: $P=0.010$ and AS_Right: $\mathrm{P}=0.018$ ); 3 - Forced Vital Capacity in Inspiration (SCM_Right: $P=0.018$; AS_Right: $P=0.018$ and AS_Left: $P=0.046) ; 4$ - Maximal Inspiratory Pressure (SCM_Left: $P=0.007$ and $A E \_L e f t: ~ P<0.033$ ) e; 5 - Maximal Expiratory Pressure (SCM_right: $P=0.005$; SCM_Left: $P=0.018 ; A S \_R i g h t: P=0.017$ and AS_Left: $P=0.004$ ), showing that the RMS values of the sEMG signal increased in the post-intervention physiotherapeutic evaluation (Table 1).

When analysing the Threshold group (pre and post-intervention), there were statistically significant differences for the following tests: 1 - Dynamometry (SCM_Right: $P=0.005$; SCM_Left: $P=0.001$; AS_Right: $P=0.002$ and AS_Left: $P=0.004) ; 2$ - Vital Capacity ( $S C M$ Right: $P=0.005$; SCM_Left: $P=0.005$; AS_Right: $P=0.006$ and AS_Left: $P=0.002) ; 3$ - Forced Vital Capacity in Inspiration (SCM_Left: $P=0.001$ and AS_Left: $P=0.037) ; 4$ - Forced Vital Capacity in Expiration (SCM_Left: $P=0.041$ ); 5 - Maximal Inspiratory Pressure (SCM_Right: $P=0.007$; $S C M$ Left: $P=0.001$; AS_Right: $P=0.001$ and $A S$ Left: $P=0.002$ ); and; 6 - Maximal Expiratory Pressure (SCM_Right: $P=0.047$; AS_Right: $P=0.008$ and AS_Left: $P=0.008$ ), likewise showing an increase in the RMS values of the sEMG signal after physiotherapeutic intervention (Table 2).

The comparison of electromyographic activity (RMS) between right vs. left sides for the "Maneuvers" group, showed no statistically significant differences $(P>0.05)$ for the

Table 1. Comparison of the RMS values of the SEMG, pre- and post-intervention for the "Maneuvers" group.

\begin{tabular}{|c|c|c|c|c|}
\hline \multirow{2}{*}{ Evaluation } & \multirow{2}{*}{ Muscles_side } & \multicolumn{2}{|c|}{ Evaluation } & \multirow{2}{*}{ P Valor } \\
\hline & & Pre & Post & \\
\hline \multirow{4}{*}{ Dynamometry (kgf) } & SCM_Rigth & $0.40 \pm 0.08$ & $0.74 \pm 0.45$ & $0.002 \diamond$ \\
\hline & SCM_Left & $0.33 \pm 0.09$ & $0.41 \pm 0.32$ & 0.0100 \\
\hline & AS_Rigth & $0.33 \pm 0.16$ & $0.60 \pm 0.47$ & $0.091 \neq$ \\
\hline & AS_Left & $0.35 \pm 0.09$ & $0.48 \pm 0.27$ & $0.018 \neq$ \\
\hline \multirow{4}{*}{ Vital Capacity (I) } & SCM_Rigth & $0.19 \pm 0.10$ & $0.42 \pm 0.47$ & $0.018 \neq$ \\
\hline & SCM_Left & $0.18 \pm 0.07$ & $0.28 \pm 0.31$ & 0.0100 \\
\hline & AS_Right & $0.23 \pm 0.15$ & $0.35 \pm 0.35$ & 0.0180 \\
\hline & AS_Left & $0.20 \pm 0.09$ & $0.29 \pm 0.22$ & $0.063 \neq$ \\
\hline
\end{tabular}

Note: RMS = Root Mean Square; SCM_Rigth = Sternocleidomastoid right; SCM_Left = Sternocleidomastoid left; AS_Rigth = Anterior Scalene right; AS_Left $=$ Anterior Scalene left; $F V C=$ forced vital capacity; $\mathrm{PI}_{\max }=$ maximal Inspiratory Pressure; $\mathrm{PE}_{\max }=$ maximal Expiratory Pressure; $k g f=$ kilogram-force; $\mathrm{I}=$ litre; $\mathrm{cmH} 2 \mathrm{O}=$ centimeters of water; $\diamond$ Student $t$ test (paired); $\neq$ Wilcoxon's test. 
Table 1. Continued...

\begin{tabular}{|c|c|c|c|c|}
\hline \multirow{2}{*}{ Evaluation } & \multirow{2}{*}{ Muscles_side } & \multicolumn{2}{|c|}{ Evaluation } & \multirow{2}{*}{ P Valor } \\
\hline & & Pre & Post & \\
\hline \multirow{4}{*}{ FVC_Inspiration (I) } & SCM_Rigth & $0.27 \pm 0.12$ & $0.59 \pm 0.62$ & $0.018 \neq$ \\
\hline & SCM_Left & $0.26 \pm 0.11$ & $0.47 \pm 0.42$ & 0.0850 \\
\hline & AS_Rigth & $0.28 \pm 0.09$ & $0.51 \pm 0.36$ & $0.018 \neq$ \\
\hline & AS_Left & $0.35 \pm 0.12$ & $0.66 \pm 0.33$ & 0.0460 \\
\hline \multirow{4}{*}{ FVC_Expiration (I) } & SCM_Rigth & $0.38 \pm 0.13$ & $0.44 \pm 0.43$ & $0.128 \neq$ \\
\hline & SCM_Left & $0.29 \pm 0.12$ & $0.48 \pm 0.40$ & 0.8620 \\
\hline & AS_Rigth & $0.29 \pm 0.13$ & $0.38 \pm 0.23$ & 0.1650 \\
\hline & AS_Left & $0.32 \pm 0.17$ & $0.44 \pm 0.32$ & 0.2370 \\
\hline \multirow{4}{*}{$\mathrm{PI}_{\max }(\mathrm{cmH} 2 \mathrm{O})$} & SCM_Rigth & $0.34 \pm 0.15$ & $0.35 \pm 0.24$ & 0.0630 \\
\hline & SCM_Left & $0.36 \pm 0.14$ & $0.56 \pm 0.68$ & 0.0070 \\
\hline & AS_Rigth & $0.32 \pm 0.13$ & $0.44 \pm 0.43$ & 0.1090 \\
\hline & AS_Left & $0.29 \pm 0.18$ & $0.32 \pm 0.14$ & 0.0330 \\
\hline \multirow{4}{*}{$P E_{\max }(\mathrm{cmH} 2 \mathrm{O})$} & SCM_Rigth & $0.33 \pm 0.12$ & $0.47 \pm 0.57$ & 0.0050 \\
\hline & SCM_Left & $0.32 \pm 0.09$ & $0.38 \pm 0.22$ & $0.018 \neq$ \\
\hline & AS_Rigth & $0.33 \pm 0.15$ & $0.44 \pm 0.26$ & 0.0170 \\
\hline & AS_Left & $0.29 \pm 0.12$ & $0.32 \pm 0.27$ & $0.004 \diamond$ \\
\hline
\end{tabular}

Note: RMS = Root Mean Square; SCM_Rigth = Sternocleidomastoid right; SCM_Left = Sternocleidomastoid left; AS_Rigth = Anterior Scalene right; AS_Left = Anterior Scalene left; $\mathrm{FVC}=$ forced vital capacity; $\mathrm{PI}_{\max }=$ maximal Inspiratory Pressure; $\mathrm{PE}_{\max }=$ maximal Expiratory Pressure; $\mathrm{kgf}=\mathrm{kilogram}$-force; $\mathrm{I}=$ litre; $\mathrm{cmH} 2 \mathrm{O}=$ centimeters of water; $\diamond$ Student $t$ test (paired); $\neq$ Wilcoxon's test.

Table 2. Comparison of RMS values of the EMG signal, pre- and post-intervention for the "Threshold" group.

\begin{tabular}{|c|c|c|c|c|}
\hline \multirow{2}{*}{ Evaluation } & \multirow{2}{*}{ Muscles_side } & \multicolumn{2}{|c|}{ Evaluation } & \multirow{2}{*}{ P Valor } \\
\hline & & Pre & Post & \\
\hline \multirow{4}{*}{ Dynamometry (kgf) } & SCM_Rigth & $0.44 \pm 0.14$ & $0.64 \pm 0.39$ & $0.005 \neq$ \\
\hline & SCM_Left & $0.38 \pm 0.17$ & $0.67 \pm 0.66$ & 0.0010 \\
\hline & AS_Rigth & $0.41 \pm 0.19$ & $0.54 \pm 0.25$ & 0.0020 \\
\hline & AS_Left & $0.41 \pm 0.14$ & $0.50 \pm 0.27$ & 0.0040 \\
\hline \multirow{4}{*}{ Vital Capacity (I) } & SCM_Rigth & $0.22 \pm 0.09$ & $0.37 \pm 0.37$ & 0.0010 \\
\hline & SCM_Left & $0.25 \pm 0.10$ & $0.47 \pm 0.32$ & $0.005 \neq$ \\
\hline & AS_Right & $0.26 \pm 0.13$ & $0.40 \pm 0.34$ & 0.0060 \\
\hline & AS_Left & $0.28 \pm 0.09$ & $0.42 \pm 0.25$ & 0.0020 \\
\hline \multirow{4}{*}{ FVC_Inspiration (I) } & SCM_Rigth & $0.38 \pm 0.14$ & $0.57 \pm 0.41$ & $0.126 \neq$ \\
\hline & SCM_Left & $0.38 \pm 0.11$ & $0.77 \pm 1.10$ & 0.0010 \\
\hline & AS_Rigth & $0.45 \pm 0.11$ & $0.50 \pm 0.36$ & $0.508 \neq$ \\
\hline & AS_Left & $0.41 \pm 0.14$ & $0.87 \pm 0.77$ & $0.037 \neq$ \\
\hline \multirow{4}{*}{ FVC_Expiration (I) } & SCM_Rigth & $0.32 \pm 0.17$ & $0.44 \pm 0.37$ & $0.593 \neq$ \\
\hline & SCM_Left & $0.33 \pm 0.15$ & $0.58 \pm 0.37$ & 0.0410 \\
\hline & AS_Rigth & $0.35 \pm 0.15$ & $0.42 \pm 0.21$ & 0.6710 \\
\hline & AS_Left & $0.28 \pm 0.14$ & $0.44 \pm 0.25$ & 0.3980 \\
\hline \multirow{4}{*}{$\mathrm{PI}_{\max }(\mathrm{cmH} 2 \mathrm{O})$} & SCM_Rigth & $0.43 \pm 0.11$ & $0.79 \pm 0.61$ & $0.007 \diamond$ \\
\hline & SCM_Left & $0.43 \pm 0.11$ & $1.13 \pm 0.74$ & 0.0010 \\
\hline & AS_Rigth & $0.40 \pm 0.13$ & $0.69 \pm 0.50$ & 0.0010 \\
\hline & AS_Left & $0.41 \pm 0.13$ & $1.07 \pm 0.99$ & 0.0020 \\
\hline \multirow{4}{*}{$\mathrm{PE}_{\max }(\mathrm{cmH} 2 \mathrm{O})$} & SCM_Rigth & $0.48 \pm 0.41$ & $1.10 \pm 2.48$ & 0.0470 \\
\hline & SCM_Left & $0.35 \pm 0.12$ & $0.59 \pm 0.55$ & 0.2410 \\
\hline & AS_Rigth & $0.53 \pm 0.39$ & $0.74 \pm 0.85$ & 0.0080 \\
\hline & AS_Left & $0.38 \pm 0.17$ & $0.59 \pm 0.67$ & $0.008 \neq$ \\
\hline
\end{tabular}

Note: RMS = Root Mean Square; SCM_ Rigth = Sternocleidomastoid right; SCM_Left = Sternocleidomastoid left; AS_Rigth = Anterior Scalene right; AS_Left $=$ Anterior Scalene left; $F V C=$ forced vital capacity; $\mathrm{PI}_{\max }=$ maximal Inspiratory Pressure; $\mathrm{PE}_{\max }=$ maximal Expiratory Pressure; $\mathrm{kgf}=\mathrm{kilogram}$-force; $\mathrm{I}=$ litre; $\mathrm{cmH} 2 \mathrm{O}=$ centimeters of water; $\diamond$ Student $t$ test (paired); $\neq$ m Wilcoxon's test. 
evaluated two muscles (SCM and AS), for all the performed tests (Dynamometry, Vital Capacity, Forced Vital Capacity in Expiration, Forced Vital Capacity in Inspiration, Maximal Inspiratory Pressure and Maximal Expiratory Pressure), both in the pre and post intervention evaluations. For Threshold group, a statistically significant difference in the SCM muscle during dynamometry ( $P=0.009)$ and forced vital capacity $(P=0.001)$ in the post-intervention evaluation was observed (Table 3).

\section{DISCUSSION}

In the present study, the main findings showed an increase in the handgrip strength for the Maneuver group and in the surface electromyographic (sEMG) activity of the SCM and SA muscles during most of the tests (dynamometry, VC, FVC in Inspiratory and Maximal Expiratory Pressure) for the 2 experimental groups (Maneuvers and Threshold). These results corroborate with Farias et al. ${ }^{(27)}$ findings when analyzing 34 individuals (aerobic training and control group) during 8 weeks, and identified significant improvement in muscle strength. Similar results were also reported by Troosters et al. ${ }^{(15)}$, who observed, in a meta-analysis study, an improvement in exercise tolerance due to a combination of increased strength and peripheral muscle endurance in individuals with COPD undergoing protocols of aerobic training. In another study developed by Troosters et al. ${ }^{(28)}$ with 100 individuals with COPD divided into two groups (control and aerobic training + strength) during 6 weeks, it was observed an increase in peripheral muscle strength for the group that performed the training protocol. Thus, aerobic training showed an important role in minimizing secondary damage to COPD, as reported in this study, even considering that we only used aerobic training on a treadmill. On the other hand, Mattioli et al. ${ }^{(29)}$, when

Table 3. Comparison of RMS values of the sEMG between the rigth and left sides for the "Threshold" group.

\begin{tabular}{|c|c|c|c|c|}
\hline \multirow{2}{*}{ Muscles } & \multirow{2}{*}{ Threshold } & \multicolumn{2}{|c|}{ Sides } & \multirow{2}{*}{ P Valor } \\
\hline & & Rigth & Left & \\
\hline \multirow[t]{12}{*}{ SCM } & Dina_Pre & $0.44 \pm 0.14$ & $0.42 \pm 0.12$ & $0.690 \square$ \\
\hline & Dina_Post & $1.72 \pm 1.20$ & $0.84 \pm 0.19$ & $0.009 *$ \\
\hline & VC_Pre & $0.22 \pm 0.09$ & $0.22 \pm 0.11$ & $0.930 \square$ \\
\hline & VC_Post & $0.80 \pm 0.42$ & $1.02 \pm 0.52$ & $0.912 *$ \\
\hline & FVC_Insp_Pre & $0.38 \pm 0.14$ & $0.38 \pm 0.11$ & $0.808 \square$ \\
\hline & FVC_Insp_Post & $0.57 \pm 0.41$ & $1.21 \pm 0.27$ & $0.001 *$ \\
\hline & FVC_Exp_Pre & $0.37 \pm 0.13$ & $0.35 \pm 0.18$ & $0.862 \square$ \\
\hline & FVC_Exp_Post & $0.44 \pm 0.37$ & $0.58 \pm 0.37$ & $0.481 *$ \\
\hline & $\mathrm{PI}_{\max }$ Pre & $0.43 \pm 0.11$ & $0.43 \pm 0.11$ & $0.952 \square$ \\
\hline & $\mathrm{PI}_{\max }$ Post & $0.99 \pm 0.32$ & $0.99 \pm 0.34$ & $0.994 \square$ \\
\hline & $\mathrm{PE}_{\max }$ Pre & $0.48 \pm 0.41$ & $0.35 \pm 0.13$ & $0.579 *$ \\
\hline & $P E_{\max -}$ Post & $1.13 \pm 0.65$ & $1.03 \pm 0.56$ & $0.729 \square$ \\
\hline \multirow[t]{12}{*}{ AS } & Dina_Pre & $0.41 \pm 0.19$ & $0.41 \pm 0.14$ & $0.356 \square$ \\
\hline & Dina_Post & $0.95 \pm 0.21$ & $0.95 \pm 0.36$ & $0.982 \square$ \\
\hline & VC_Pre & $0.26 \pm 0.13$ & $0.28 \pm 0.09$ & $0.756 \square$ \\
\hline & VC_Post & $0.80 \pm 0.42$ & $1.02 \pm 0.52$ & $0.309 \square$ \\
\hline & FVC_Insp_Pre & $0.37 \pm 0.07$ & $0.39 \pm 0.08$ & $0.608 \square$ \\
\hline & FVC_Insp_Post & $0.50 \pm 0.36$ & $0.87 \pm 0.77$ & $0.436 *$ \\
\hline & FVC_Exp_Pre & $0.40 \pm 0.18$ & $0.39 \pm 0.15$ & $0.895 \square$ \\
\hline & FVC_Exp_Post & $0.42 \pm 0.21$ & $0.44 \pm 0.25$ & $0.820 \square$ \\
\hline & $\mathrm{PI}_{\max -}$ Pre & $0.40 \pm 0.13$ & $0.41 \pm 0.13$ & $0.903 \square$ \\
\hline & $\mathrm{PI}_{\max }$ Post & $1.09 \pm 0.37$ & $0.86 \pm 0.27$ & $0.130 \square$ \\
\hline & $P E_{\text {max }}$ Pre & $0.56 \pm 0.36$ & $0.41 \pm 0.12$ & $0.247^{*}$ \\
\hline & $\mathrm{PE}_{\text {max }}$ Post & $0.70 \pm 0.30$ & $0.94 \pm 0.45$ & $0.190 *$ \\
\hline
\end{tabular}

Note: RMS = Root Mean Square; SCM = Sternocleidomastoid; AS = Anterior Scalene; Dina_Pre = dinamometry pre-intervention; Dina_Post = dinamometry post-intervention; VC Pre $=$ Vital Capacity pre-intervention; VC Post $=$ Vital Capacity post-intervention; FVC_Insp_Pre $=$ forced vital capacity in inspiration pre-intervention; FVC_Insp_Post $=$ forced vital capacity in inspiration post-intervention; FVC_Exp_Pre = forced vital capacity in the expiration pre-intervention; FVC_Exp_Post $=$ forced vital capacity in expiration post-intervention; $\mathrm{PI}_{\max -} \mathrm{Pre}=$ maximal Inspiratory Pressure Pre-intervention; $\mathrm{PI}_{\max -}$ Post $=$ maximal Inspiratory Pressure Post-intervention; $\mathrm{PE}{ }_{\max -}$ Pre $=$ maximal Expiratory Pressure Pre-intervention; $\mathrm{PE}_{\max -}$ Post = maximal Expiratory Pressure Post-intervention; $\square=$ Student $t$ test (unpaired); *Man-Whitney's test. 
analyzing 53 active elderly, divided into 3 groups according to the their physical exercise (gymnastic, hydrogymnastic and strength training), observed that strength training group presented higher strength averages when comparing to the other ones. Even without performing resistance exercises, our results showed that the Maneuver group increased the handgrip strength.

Results of the SCM and AS muscles' electromyographic activity between pre and post-intervention showed an increase in RMS mean values in both muscles (SCM and AS) for the Maneuvers group on the following tests: handgrip, vital capacity (VC), forced vital capacity in inspiration (FVC_Insp), maximal inspiratory pressure (PImax) and maximal expiratory pressure (PEmax). These results partially corroborate with Cardoso et al. (14), when carrying out a study with 25 individuals (13 control group; 12 COPD group), submitted to EPAP evaluation during 25 minutes, with SCM and AS muscles' electromyography, and observed significant alteration only for the SCM muscle. In this sense, Brasileiro-Santos et al. ${ }^{(30)}$ observed, during the PImax maneuver, an increase in SCM and AS muscles activity due to increased respiratory effort. These results were also reported by Yokoba et al.(16) when analyzing the sEMG of different muscles (scalene, SCM, trapezius and transverse abdominus) during the manovacuometry in healthy individuals. The authors found a progressive increase in the recruitment of these muscles during the PImax maneuver, although they did not adopt a pulmonary rehabilitation program, which allows comparing differences in electromyographic activity before and after an intervention. Similarly to the results from the Maneuvers group, when comparing the Threshold group's sEMG (pre- and post-intervention), increased RMS mean values were observed on both right and left muscles (SCM and AS) for the performed tests (handgrip, vital capacity (VC), forced vital capacity on inspiration (FVC_Insp), maximal inspiratory pressure (PImax) and maximal expiratory pressure (PEmax). These findings corroborate with the study developed by Dornelas-Andrade et al. ${ }^{(21)}$ which identified, in 14 elderly patients (7 COPD and 7 healthy), a $28 \%$ increase in myoelectric activity for the SCM muscle for the COPD group after an inspiratory muscle training (6 consecutive days), through the electromyographic signal collected during 7 minutes in the first, fourth and sixth days.

Dumke et al. ${ }^{(17)}$ performed a study with 30 men with COPD and 30 controls, capturing the electromyographic signal of the scalene, SCM and intercostal muscles during inspiratory capacity (IC) obtained in the vital capacity maneuver. They observed a significant increase in SEMG signal amplitude for the right and left scalenes, when compared to the control group. The results highlight that COPD individuals have a higher recruitment of the accessory musculature of the breath during the IC measurement than healthy individuals. In the comparison between sides, the present study did not observe changes during all the tests for the Maneuvers group, whereas for the Threshold group, a difference was observed after SCM intervention, on handgrip strength and forced vital capacity. In general, the results of the present study for the Maneuvers group corroborate the data of Cardoso et al.(14), who verified the SCM and AS muscles' behavior between the right and left segments and observed that they were not influenced by positive expiratory pressure through EPAP. Concerning the sEMG signal decrease of the left SCM, during the post-intervention handgrip strength test, it was not possible to find a plausible response to this fact. However, the sEMG signal increase in the FVC test during inspiration may have been influenced by the positioning or movement of the neck when executing the maneuver.

This study presents limitations that must be higlighted: the low number of individuals and treatment sessions, which may have influenced the results; besides the lack of evidence associating the use of sEMG with the other evaluation methods (dynamometry, spirometry and maximal inspiratory and expiratory pressure), pre- and post-intervention, thus limiting the results extrapolation.

\section{CONCLUSIONS}

The results of the present study revealed that the proposed physiotherapeutic treatment promoted increases: 1 ) in the handgrip strength for the Threshold group; 2 ) in the electrical activity of the breathing accessory muscles (SCM and AS), contradicting, in part, the hypothesis presented previously. This increase in the amplitude of the EMG signal of the analyzed muscles suggests a greater thoracic expandability, with possible gains in ventilatory parameters. The promising result evidenced in this study, and also the low cost of the proposed physiotherapeutic intervention, suggest the implementation of these protocols in public health services, in order to improve the quality of life of patients of COPD.

\section{AUTHORS' CONTRIBUTIONS}

SMLM: Data collection + Preparation of the manuscript; DMM: Data collection + Preparation of the manuscript; AFG: Data collection + Preparation of the manuscript; MASS: Data collection + Preparation of the manuscript; GFPW: Revision of the manuscript; SSM: Revision of the manuscript; CMLM: Revision and translation of the manuscript; HHS: Statistical treatment + Preparation + Revision of the manuscript. SMLM, DMM, AFG, MASS, GFPW, SSM, CMLM e $H H S$, performed the critical intellectual review of the manuscript and all authors read and approved the final manuscript.

\section{CONFLICTS OF INTEREST}

The authors declare that they have no competing interests.

\section{AUTHORS DETAILS}

${ }^{1}$ Curso de Fisioterapia da Universidade Federal da Paraíba - UFPB, João Pessoa, Paraíba, Brasil.

Departamento de Promoção e Saúde da Universidade Federal da Paraíba UFPB, João Pessoa, Paraíba, Brasil.

\section{REFERENCES}

1. Global Strategery for the Diagnosis, Management, and Prevention of COPD: Global Intiative for Chronic Obstructive Lung Disease (GOLD) 2013. 
2. Dourado VZ, Tanni SE, Faganello MM, Sanchez FF, Godoy I. Manifestações sistêmicas na doença pulmonar obstrutiva crônica. J Bras Pneumol. 2006; 32(2):161-71.

3. Cardoso EK, Cunha M, Nakamura MAM. Análise eletromiográfica dos músculos esternocleidomastóideo em pacientes com DPOC após técnica de respiração diafragmática. Rev Inspirar Mov Saúde. 2013; 5(1):1-5.

4. Gomes CF, Trezza EMC, Murade ECM, Padovani CR. Avaliação eletromiográfica com eletrodos de captação de superfície dos músculos masseter, temporal e bucinador de lactentes em situação de aleitamento natural e artificial. J Pediatr. 2006; 82(2):103-9.

5. Correa CS, Costa R, Pinto RS. Utilização de diferentes técnicas para o controle do posicionamento dos eletrodos de superfície na coleta do sinal eletromiográfico. Rev. Acta Bras Mov Hum. 2012; 2(2):5-13.

6. Jagoe RT, Engelen MPKJ. Muscle wasting and changes in muscle protein metabolism in chronic obstructive pulmonary disease. Eur Respir J. 2003; 22(46):52-63.

7. Neder JA, Sword D, Ward AS, Mackay E, Cochrane LM, Clark CJ. Home based neuromuscular electrical stimulation as a new rehabilitative strategy for severely disabled patients with chronic obstructive pulmonary disease (COPD). Thorax. 2002; 57(4):333-7.

8. Benetti G, Schneider P, Meyer F. Os benefícios do esporte e a importância da treinabilidade da força muscular de pré-púberes atletas de voleibol. Rev Bras Cineantropom Desempenho Hum. 2005; 7(2):87-93.

9. Dourado VZ, Godoy I. Recondicionamento muscular na DPOC: principais intervenções e novas tendências. Rev Bras Med Esporte. 2004; 10(4):3314.

10. Moreira D, Alvarez RRA. Avaliação da força de preensão palmar com o uso do dinamômetro Jamar ${ }^{\circ}$ em pacientes portadores de hanseníase atendidos em nível ambulatorial no Distrito Federal. Hansen Int. 2002; 27(2):61-9.

11. Schlussel MM, Anjos LA, Kac, G. A dinamometria manual e seu uso na avaliação nutricional. Rev Nutr. 2008; 21(2):223-35.

12. Ike D, Jamami M, Marino DM, Ruas G, Pessoa BV, Di Lorenzo VAP. Efeitos do exercício resistido de membros superiores na força muscular periférica e na capacidade funcional do paciente com DPOC. Fisioter. Mov. 2010; 23(3):429-37

13. Silva KM, Bromerschenckel AIM. Fisioterapia respiratória nas doenças pulmonares obstrutivas crônicas. Rev HUPE. 2013; 12(2):94-100.

14. Cardoso DM, Paiva DN, Albuquerque IM, Jost RT, Paixão AV. Efeitos da pressão positiva expiratória nas vias aéreas sobre a atividade eletromiográfica da musculatura acessória da inspiração em portadores de DPOC. J Bras Pneumol. 2011; 37(1):46-53.

15. Troosters T, Casaburi R, Gosselink R, Decramer M. Pulmonary rehabilitation in Chronic Obstructive Pulmonary Disease. Am J Respir Crit Care Med. 2005; 172(1):19-38.

16. Yokoba M, Abe T, Katagiri M, Tomita T, Easton PA. Respiratory muscle electromyogram and mouth pressure during isometric contraction. Respir Physiol Neurobiol. 2003; 137(3):51-60.
17. Dumke A, Falkembach D, Tomasini K, Diefenthaeler F, Vaz MA, Knorst MM. Pacientes com doença pulmonar obstrutiva crônica (DPOC) tem maior ativação dos músculos acessórios da respiração que indivíduos sem DPOC [dissertação]. Porto Alegre (RS): Univ. Federal do Rio Grande do Sul; 2012.

18. Beck TW. The importance of a priori sample size estimation in strength and conditioning research. J Strength Cond Res. 2013; 27(8):2323-37.

19. Hermens HJ, Freriks B, Disselhorst-Klug C, Rau G. Development of recommendations for SEMG sensors and sensor placement procedures. J Electromyogr Kinesiol. 2000; 10(5):361-74.

20. Falla D, Dall'Alba P, Rainoldi A, Merletti R, Jull G. Location of innervation zones of sternocleidomastoid and scalene muscles: a basis for clinical and research electromyography applications. Clin Neurophysiol. 2002; 113(1):57-63.

21. Dornelas-Andrade A, Silva TNS, Vasconcelos H, Marcelino M, RodriguesMachado MG, Filho VCG, et al. Inspiratory muscular activation during threshold therapy in elderly healthy and patients with COPD. J Electromyogr Kinesiol. 2005; 15(6):631-9.

22. Ferreira ACC, Shimano AC, Mazze N, Barbieri CH, Elui VMC, Fonseca MCR. Força de preensão palmar e pinças em indivíduos sadios entre 6 e 19 anos. Acta Ortop Bras. 2011; 19(2):92-7.

23. Silva Neto LS, Karnikowiski MGO, Tavares AB, Lima RM. Associação entre sarcopenia, obesidade sarcopênica e força muscular com variáveis relacionadas de qualidade de vida em idosos. Rev Bras Fisioter. 2012; 16(5):360-7.

24. Kunikoshita LN, Silva YP, Silva TLP, Costa D, Jamami M. Efeitos de três programas de fisioterapia respiratória (PFR) em portadores de DPOC. Rev Bras Fisioter. 2006; 10(4):449-55.

25. Langer D, Probst VS, Pitta F, Burtin C, Wendriks E, Schans CPVD, et al. Guia para a prática clínica: fisioterapia em pacientes com Doença Pulmonar Obstrutiva Crônica (DPOC). Rev Bras Fisioter. 2009; 13(3):183-204.

26. Araújo AGF, Barbosa GM, Freire RA, Andrade PR, Ferreira JJA, Santos HH. Fidedignidade das medidas inter e intra-testes com goniômetro universal e artrômetro podálico da amplitude ativa de eversão e inversão do tornozelo. Fisioter Pesqui. 2014; 21(4):339-45.

27. Farias CC, Resqueti V, Dias FAL, Borghi-Silva A, Arena R, Fregonezi GAF. Costs and benefits of pulmonary rehabilitation in Chronic Obstructive Pulmonary Disease: a randomized controlled trial. Braz J Phys Ther. 2014; 18(2):165-73.

28. Troosters T, Gosselink R, Decramer M. Short- and long-term effects of outpatient rehabilitation in patients with Chronic Obstructive Pulmonary Disease: a randomized trial. Am J Med. 2000; 109(3):207-12.

29. Mattioli, RA, Cavalli AS, Ribeiro JAB, Silva MC. Associação entre força de preensão manual e atividade física em idosos hipertensos. Rev Bras Geriatr Gerontol. 2015; 18(4):881-91.

30. Brasileiro-Santos MS, Lima AMJ, Hunka MBBS, Neves TS, Andrade MA, Santos AC. Atividade mioelétrica dos músculos respiratórios em crianças asmáticas durante manobra inspiratória máxima. Rev Bras Saúde Matern Infant. 2012; 12(3):251-7. 